\title{
An analysis of visual oddity concept learning in a California sea lion (Zalophus californianus)
}

\author{
PETRA HILLE \\ Westfälische Wilhelms-Universität Münster, Münster, Germany \\ and \\ GUIDO DEHNHARDT and BJÖRN MAUCK \\ Ruhr-Universität Bochum, Bochum, Germany
}

\begin{abstract}
We tested a California sea lion for visual oddity learning by presenting problems composed of three two-dimensional black-and-white stimuli, two identical $(\mathrm{S}-)$ and one different $(\mathrm{S}+)$. In the first experimental stage, a single problem per session was presented until learning criterion was reached. In the second experimental stage, all problems were presented only five times in succession; then a new problem was introduced (six problems/session). In the third experimental stage, each problem was presented only once. The sea lion mastered all stages of oddity learning. A final transfer test with oddity problems composed of completely new stimuli yielded performance significantly above chance. Data analyses suggested learning of specific stimulus properties in the first stage, learning set formation in the second stage, but oddity conceptualization in the third stage.
\end{abstract}

Regarded as knowledge that facilitates categorization (Barsalou 1992), concepts promote cognitive economy (Rosch, 1978) and thus help organisms navigate through the maze of ever-changing stimuli in the environment (Domjan, 1998). By abstracting and generalizing information about their specific environment, animals can form concepts (Rensch, 1973) that may facilitate decisions and thus help them survive.

There has been considerable debate about the nature, kinds, and structure of concepts and the attempt to find a hierarchy of concepts (see, e.g., Fodor, 1998; Medin, 1989; Medin \& Coley, 1998; Zentall, Galizio, \& Critchfield, 2002). On the basis of logical operations (negation, conjunction, disjunction, and implication) derived from more philosophical considerations (Turner, 1967), Thomas and Crosby (1977) provided a short but valuable definition of class concepts as opposed to relational concepts. This distinction was also implemented in the learning-intelligence hierarchy presented by Thomas (1980), which is largely a synthesis of the hierarchy of learning types described by Gagné (1970) and the concept-learning hierarchy described by Bourne (1970). Accordingly, class concepts constitute Level 6 of the eight levels of the learningintelligence hierarchy, whereas relational concepts constitute higher levels ( 7 and 8 ) of this hierarchy. Concerning the class concept level, Thomas (1980) also introduced the definitional distinction between absolute class concepts

We thank the team of the Delphinarium Münster for their support during this study. Correspondence should be addressed to B. Mauck, RuhrUniversität Bochum, Allgemeine Zoologie \& Neurobiologie, ND6/33, D44780 Bochum, Germany (e-mail: bjoern.mauck@ruhr-uni-bochum.de). (the defining features are inherent in each single stimulus; e.g., tree) and relative - sometimes also called abstractclass concepts (the defining features become apparent only with reference to at least one other stimulus; e.g., in the oddity task). Accordingly, although it is not necessary to compare stimuli in order to recognize an absolute class concept, there is a need to compare in order to recognize relative class concepts.

Oddity and sameness are two of the most commonly examined concepts in animals. One being the complement or the inverse of the other, they have also been described as "twin concepts" (Delius, 1994). Therefore, it might be supposed that an animal capable of sameness or identity concept formation should also be capable of oddity concept formation. In fact, the corresponding experimental paradigms of matching-to-sample and oddity-from-sample have sometimes been used as a rationale for quasi-interchangeability in order to study other cognitive skills in animals (e.g., numerical competence; Smirnova, Lazareva, \& Zorina, 2000). This view might be misleading, however. As Steirn and Thomas (1990) and later Thomas (1996) discussed, the degree of abstractness of both oddity and samenessdifference can be manipulated systematically. With trialunique stimuli in a three-position oddity task, oddity is always a relative class concept. When separate features of stimuli (e.g., form, size, and color; see Steirn \& Thomas, 1990) are manipulated, however, the three easiest levels of "sameness" are not abstract but are absolute class concepts, because the common features of "same" objects may be detected simply with a perceptual mechanism. In the case of simultaneous matching-to-sample tasks, this argument is consistent with early Gestalt laws (e.g., the law of proximity) that predict that neighboring stimuli 
would be perceived as a single entity, depending on the degree of their proximity and equality (Koffka, 1935). Given that some same-different tasks can therefore also be solved using absolute class concepts, it may be concluded that an animal species shown to be capable of identity concept formation may not necessarily be capable of oddity concept formation as well.

Many animal species have been tested for their concept formation abilities (for reviews, see, e.g., Roitblat \& Fersen, 1992; Thompson, 1995). Evidence for oddity concept learning by nonprimate species has sometimes been claimed by researchers using facilitated acquisition with new sets of problems (i.e., a savings in learning) as a criterion for concept formation (see, e.g., Pisacreta, Lefave, Lesneski, \& Potter, 1985). However, the use of Thomas and Noble's (1988) criterion of performance in trial-unique problems has not yet shown oddity concept learning conclusively in a nonprimate species. In this respect, one study by Lombardi, Fachinelli, and Delius (1984) might represent an exception; these researchers reported significant performance in pigeons with oddity problems presented under extinction conditions. However, as far as first-trial data analysis is concerned, neither Thomas and Noble (1988) nor Bailey and Thomas (1998) have presented strong evidence that rats can respond to oddity conceptually in five-trial tasks. In contrast, primates appear to be rather predisposed to form an oddity concept in such tasks (see, e.g., Thomas \& Boyd, 1973, for squirrel monkeys and Cebus monkeys that performed significantly above chance on the first trials of a five-trial task). Thus, possibly depending on both evolutionary and ecological factors, abstract concept formation such as oddity may be easier to demonstrate in some animal species than in others.

It has been proposed that the ability to discriminate same versus different along with other abstract concepts is of some adaptive value to marine mammals (Kastak \& Schusterman, 1992). Although the marine environment seems rather unstructured, at least with respect to visual cues, and although concrete application in the wild seems difficult to conceive, identity concept formation in visual tasks has been tested repeatedly, especially with the California sea lion (Kastak \& Schusterman, 1994; Pack, Herman, \& Roitblat, 1991). Recently, we have presented evidence for identity concept formation in a harbor seal (Mauck \& Dehnhardt, 2005), a pinniped species formerly supposed to be incapable of this kind of concept formation. In that study, we concluded that the demonstration of identity concept formation in animals assumed to be incapable of such conceptualization may be contingent on the use of an appropriate method, such as multiple-choice matching. Similarly, formation of an oddity concept may be contingent on presenting the animal with a task that is sufficiently motivating to make application of other strategies, such as acquiring stimulus-specific rules or learning sets, less rewarding. Although there is a hierarchy in cognitive processes, an animal will likely use all the processes of which it is capable, concurrently, in serial and in paral- lel (Thomas, 1996). Identifying the processes that underlie the performance of single subjects as well as concluding whether or not a concept has been used is often facilitated by so-called microgenetic data analyses, as has previously been shown in both comparative (e.g., Oden, Thompson, \& Premack, 1990) and developmental (Siegler \& Crowley, 1991) research. We therefore tested oddity learning in a California sea lion - a pinniped species assumed to be capable of identity concept formation-in three experimental stages of increasing stringency (i.e., presentation of one-odd problems, presentation of oddity problems in a five-trial condition, and presentation of trial-unique three-position oddity problems). In order to determine the animal's learning strategies and thus the kind of task that is sufficiently motivating to demonstrate concept formation, we conducted detailed analyses of the data obtained in the respective parts of the study.

\section{METHOD}

\section{Subject}

Owing to the scant availability of suitable test animals as well as the lengthy preparation periods required for such animals, the present investigation is a case study. It was conducted at the Delphinarium Münster, Germany, with an 8-year-old female California sea lion (Zalophus californianus). In addition to the present experiments, the animal took part in daily shows at the dolphinarium. The sea lion was fed 5-7 kg per day of freshly thawed cut herring, sprat, mackerel, and squid, supplemented with vitamins; about a quarter of the sea lion's daily diet was fed during the experiments. Because the animal was fed for the last time each day in the late afternoon, there was a natural food deprivation of approximately $16 \mathrm{~h}$ before the first session started in the morning. Typically, experiments were conducted 5 days per week, during the morning hours, in two sessions, before and after the first show. Experiments were performed on a platform while the other sea lions and dolphins kept at the dolphinarium were separated from the experimental area.

\section{Stimuli}

A total of 284 two-dimensional stimuli were used. The stimuli consisted of black figures on a white background and were designed to vary in size and shape. Figures were cut out of black paper and glued to the center of white stimulus cards $(250 \times 250 \mathrm{~mm})$. The stimulus cards were shrink wrapped in plastic to protect them from water. Twenty stimuli were used in the 10 problems of the first experimental stages. In the second and third experimental stages, 184 stimuli were used; they were combined to form new problems. The number of possible new problems obtained by combining 184 stimuli was $\Sigma_{1}^{183}=16,836$. In addition, in order to vary the presentation of the stimuli in these problems, familiar stimuli were turned by $90^{\circ}$, $180^{\circ}$, or $270^{\circ}$. All the stimuli could be used both as correct and as incorrect stimuli. A total of 80 novel stimuli were used in transfer tests with one-trial problems in the third experimental stage (20 problems in both transfer tests, for the two-position oddity test and the threeposition oddity test, respectively; i.e., there were $2 \times 40$ novel stimuli-see Figure 1).

\section{Test Apparatus and Experimental Procedure}

The test apparatus was designed for the presentation of stimuli in a simultaneous oddity task. The apparatus was installed on a platform in the dolphinarium; the sea lion could approach it by moving freely in front of it (Figure 2). The apparatus consisted of a vertical metal frame holding an opaque PVC plate $(1.4 \mathrm{~m}$ wide $X$ $1.7 \mathrm{~m} \mathrm{high}$ ), which allowed the experimenter to hide from the sea 


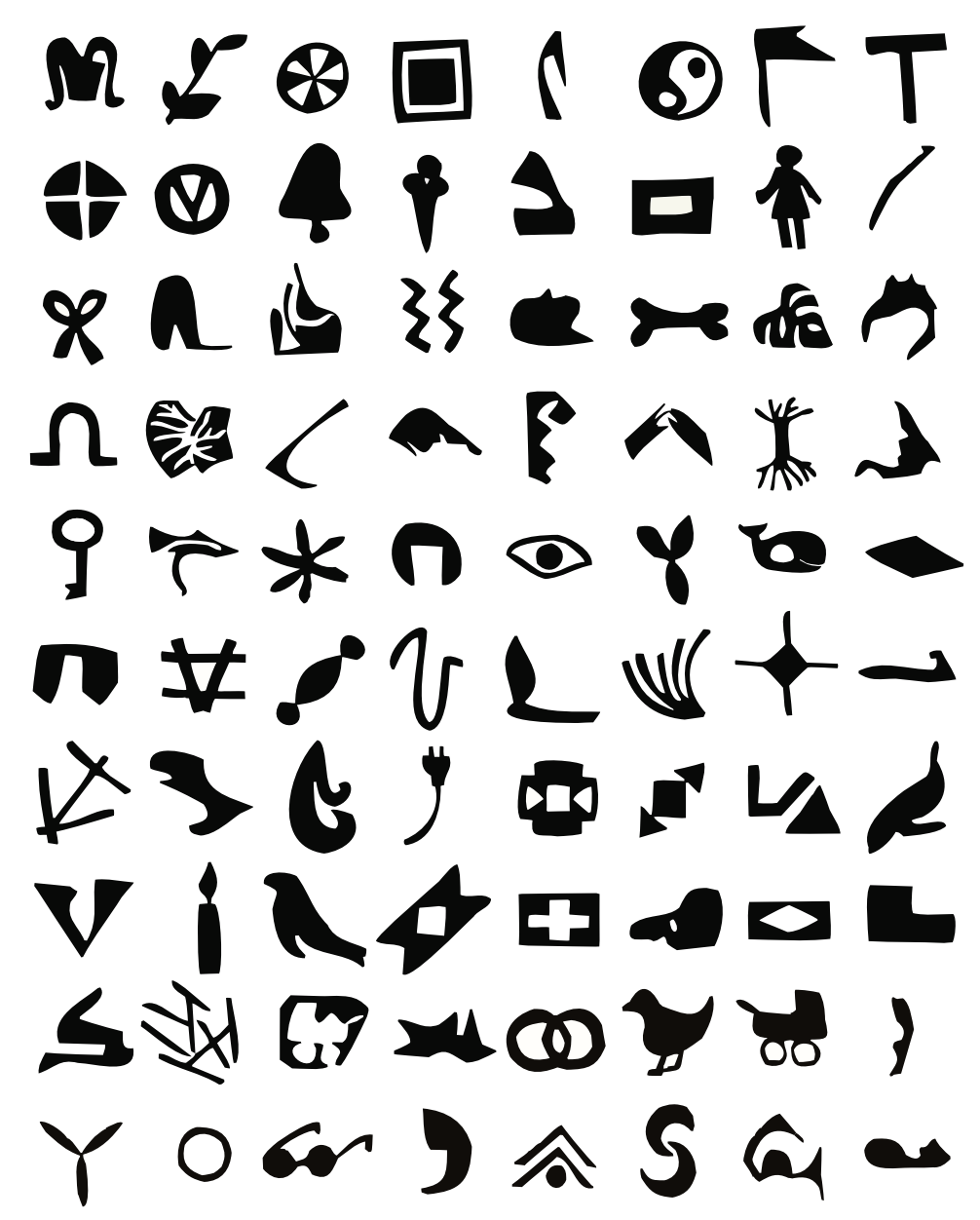

Figure 1. Stimuli used in the one-trial transfer tests (Blocks $\mathbf{N}$ and $\mathrm{P}$ ).

lion's sight in order to avoid giving unintentional cues. Three windows $(250 \times 250 \mathrm{~mm})$ were cut out beside each other in the PVC plate at a height of approximately $1 \mathrm{~m}$. The windows were covered by an opaque PVC shutter that the experimenter could raise and lower manually by means of a pulley system fixed on the upper frame. This enabled the experimenter both to control the sea lion's access to the stimuli and to exchange the stimuli without being observed by the sea lion. Stimulus plates were mounted behind the three windows in U-shaped frames that could be folded back from their vertical positions to the rear of the apparatus. Stop blocks ensured that the frames could fall back to an angle of only about $40^{\circ}$; in this position, the stimulus plates could be exchanged. When the stimuli in their respective frames were pushed against the rear of the windows again, a magnet held them in the vertical position. The sea lion could respond directly to a stimulus by opening a stimulus window, using its snout to push the stimulus out of its vertical position.

At the beginning of a trial, the stimuli were mounted behind the three windows of the apparatus, always starting from the left position. Between trials, the sea lion was allowed to move freely on the platform and in the adjacent pool. Stepping beside the apparatus, the experimenter then sent the sea lion to a starting position indicated by a mark on the platform approximately $4 \mathrm{~m}$ in front of the apparatus. As soon as the animal reached its position, the experimenter hid again behind the apparatus; from this point on, the sea lion could be observed in an observation mirror installed behind it. A trial was started when the experimenter raised the shutter, whereupon the three stimuli became visible. Two of the stimuli were exact matches, the third stimulus was the odd one. The appearance of the stimuli was the signal for the sea lion to choose. The animal had to approach the apparatus and press its snout against one of the stimulus plates to open the respective window. The sea lion was rewarded for responding to the stimulus not matching the other two stimuli. Correct choices were rewarded with pieces of cut herring; there was no punishment for incorrect choices.

\section{Experimental Stages of the Study}

Throughout the study, oddity problems were presented in several conditions. A problem refers to the simultaneous presentation of three stimuli (new or familiar), two of which are identical. In a oneodd problem, only one of the two different stimuli is used as $\mathrm{S}+$. In contrast, in a two-odd problem (not used in the present study), both stimuli can be used as $\mathrm{S}+$ and $\mathrm{S}-$. In the two-position condition, the $\mathrm{S}+$ is presented on only the two outer positions of the apparatus. In the three-position condition, the $\mathrm{S}+$ can also appear in the middle position. One-trial problems are presented only once; five-trial problems are presented five times in a row.

Presentation of simple one-odd problems constituted the first experimental stage of the study (Blocks A-J). In the second experimental stage (Blocks $\mathrm{K}$ and $\mathrm{L}$ ), five-trial problems were presented. Presentation of one-trial problems (Blocks $\mathrm{M}-\mathrm{O}$ ) and a final transfer test (Block P) constituted the third experimental stage (Table 1). 


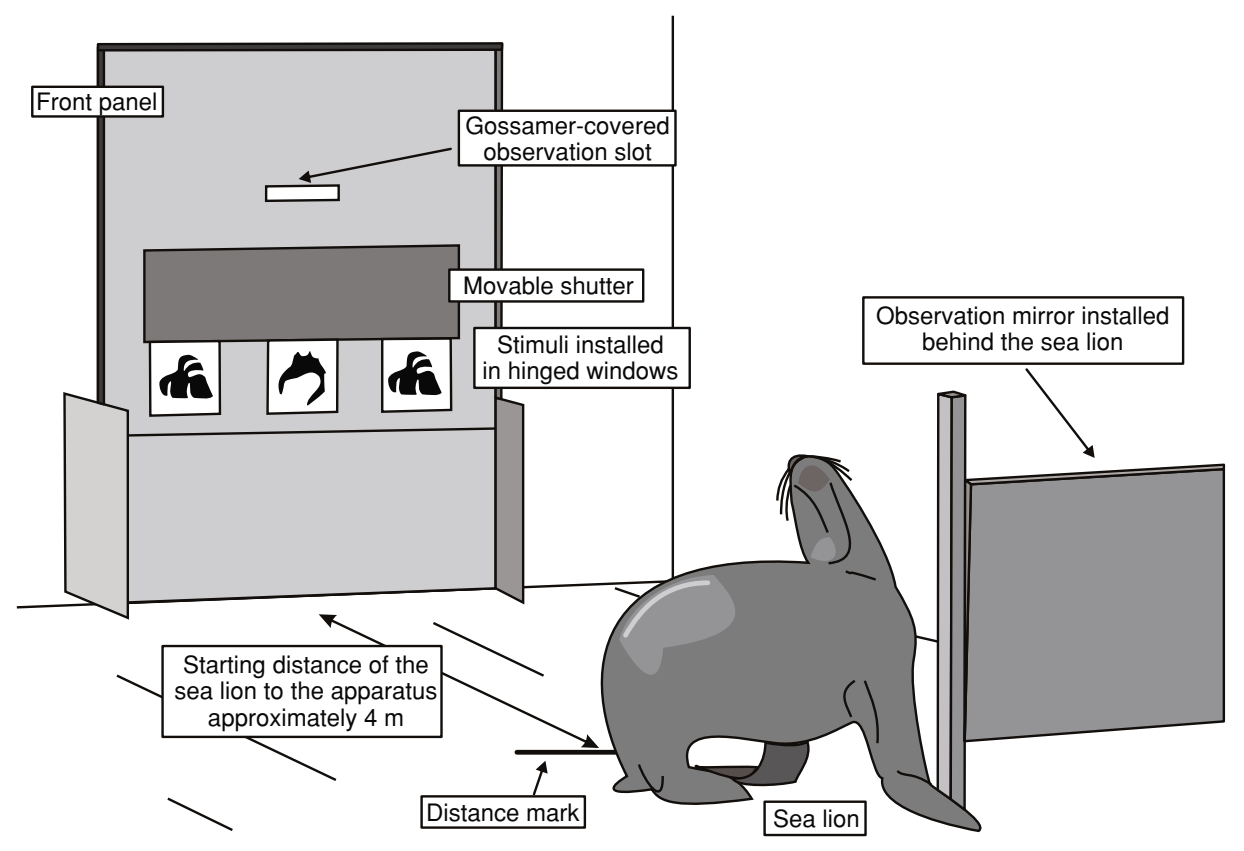

Figure 2. Schematic drawing of the experimental setup.

During presentation of one-odd problems (Blocks A-J, only one problem per session, 30 trials per session), the positive stimulus permutated over the three positions of the apparatus (three-position oddity, presentation of $\mathrm{S}+$ counterbalanced over three positions). Sessions were conducted until performance reached $90 \%$ correct choices on each problem; then a new block with a new oddity problem was started.

In the second stage, the experimental procedure involved six oneodd problems in each session (again, 30 trials per session); thus, each problem was presented for only 5 consecutive trials. The stimuli were taken from the 184-stimulus pool used for the second and part of the third experimental stages. During the first 24 sessions of this stage, the positive stimuli could appear in all three positions of the apparatus (three-position oddity, presentation of $\mathrm{S}+$ counterbalanced over three positions, Block K). During a further 10 sessions of this experimental stage, new problems were made from stimuli from the stimulus pool, and the positive stimulus was presented only in one of the two outer positions (two-position oddity, Block L).

In the first part of the third experimental stage, the sea lion was presented with one-trial problems made of stimuli taken from the stimulus pool of 184 stimuli in the two-position oddity condition (20 trials per session, presentation of S+ counterbalanced over positions, Block M). Then a transfer session was conducted (20 trials, Block N) with completely new stimuli. In the second part of the third experimental stage, one-trial problems involving stimuli from the stimulus pool were presented in the three-position oddity condition (20 trials per session, $\mathrm{S}+$ presented seven times in each outer position and six times in the central position, Block O). In a final transfer test, the sea lion was presented with 20 three-position oddity problems composed of completely new stimuli $(\mathrm{S}+$ presented seven times in each outer position and six times in the central position, Block P).

In all sessions, the position of the correct stimulus $(\mathrm{S}+$ ) followed pseudorandom schedules (Gellerman, 1933). Since each problem consisted of three stimuli presented on the three positions of the apparatus, it could be assumed that the sea lion could choose each position by chance with a probability of $p=.33$. Alternatively, since each problem in fact consisted of only two different stimuli (one of which was doubled), it can be assumed that the sea lion instead chose by deciding for one of the two different stimuli, resulting in a chance probability of $p=.5$ (Thomas \& Frost, 1983). If one assumes a chance probability of $p=.5$, the percentage of correct choices necessary for a performance significantly different from chance $(p<$ $.01 ; \chi^{2}$ test) is $73.3 \%$ correct choices in sessions with 30 trials and $80 \%$ correct choices in sessions with 20 trials. The learning criterion and the criterion for passing a transfer test were both defined as $90 \%$ correct choices per session.

\section{RESULTS}

Because the sea lion was used to basic conditioning techniques, it learned the basic experimental procedure (waiting for the stimulus presentation at the starting position, then approaching the apparatus and opening a stimulus window by pushing against the stimulus plate with its snout) without difficulty.

Trial duration was about $10 \mathrm{sec}$. Sometimes the sea lion showed a vicarious trial and error behavior by first looking between the stimuli and only then making its choice by actually opening one of the stimulus windows. The sea lion was never observed to look in the mirror; rather, it ignored its existence. Between trials, the sea lion normally swam around in the pool adjacent to the platform and only approached the experimental setup when it was called. There was no obvious difference in the motivational state of the sea lion before and after the first show.

In the first experimental stage (Blocks A-J, each with a one-odd problem), the sea lion reached the criterion ( $\geq 90 \%$ correct choices) within one to seven sessions (Table 1). Over this experimental stage, there was no increase in performance (i.e., the number of trials necessary to reach the criterion did not decrease). Chi-square tests yielded highly significant deviations from equal distributions of the sea lion's reactions to one of the three posi- 
Table 1

Experimental Stages of the Study

\begin{tabular}{|c|c|c|c|c|c|c|c|}
\hline Block & $\begin{array}{l}\text { Trials/ } \\
\text { Session }\end{array}$ & $\begin{array}{l}\text { Possible } \\
\text { Correct } \\
\text { Stimulus } \\
\text { Position }\end{array}$ & $\begin{array}{l}\text { Problems/ } \\
\text { Session }\end{array}$ & $\begin{array}{c}\text { No. } \\
\text { Sessions }\end{array}$ & $\begin{array}{l}\text { Stimulus } \\
\text { Familiarity }\end{array}$ & $\begin{array}{l}\text { No. } \\
\text { Trials }\end{array}$ & $\begin{array}{c}\% \text { Correct } \\
\text { Choices for } \\
\text { Significant } \\
\text { Performance* }\end{array}$ \\
\hline A & 30 & all 3 & 1 & 5 & new & 150 & 73.33 \\
\hline B & 30 & all 3 & 1 & 2 & new & 60 & 73.33 \\
\hline $\mathrm{C}$ & 30 & all 3 & 1 & 7 & new & 210 & 73.33 \\
\hline $\mathrm{D}$ & 30 & all 3 & 1 & 3 & new & 90 & 73.33 \\
\hline $\mathrm{E}$ & 30 & all 3 & 1 & 3 & new & 90 & 73.33 \\
\hline $\mathrm{F}$ & 30 & all 3 & 1 & 1 & new & 30 & 73.33 \\
\hline G & 30 & all 3 & 1 & 6 & new & 180 & 73.33 \\
\hline $\mathrm{H}$ & 30 & all 3 & 1 & 7 & new & 210 & 73.33 \\
\hline I & 30 & all 3 & 1 & 2 & new & 60 & 73.33 \\
\hline $\mathrm{J}$ & 30 & all 3 & 1 & 4 & new & 120 & 73.33 \\
\hline $\mathrm{K}$ & 30 & all 3 & 6 & 24 & stimulus pool & 720 & 73.33 \\
\hline $\mathrm{L}$ & 30 & 2 outer positions & 6 & 10 & stimulus pool & 300 & 73.33 \\
\hline $\mathrm{M}$ & 20 & 2 outer positions & 20 & 12 & stimulus pool & 240 & 80 \\
\hline $\mathrm{N}$ & 20 & 2 outer positions & 20 & 1 & new & 20 & 80 \\
\hline $\mathrm{O}$ & 20 & all 3 & 20 & 6 & stimulus pool & 120 & 80 \\
\hline $\mathrm{P}$ & 20 & all 3 & 20 & 1 & new & 20 & 80 \\
\hline
\end{tabular}

*According to $\chi^{2}$ test $(p<.01)$.

tions with respect to presentation of the correct stimulus in the three positions of the apparatus [left position, $\chi^{2}(2$, $N=322)=156.65, p<.001$; central position, $\chi^{2}(2, N=$ $468)=99.78, p<.001$; right position, $\chi^{2}(2, N=410)=$ $81.85, p<.001]$. Thus, there was a clear correlation between the presentation of $\mathrm{S}+$ on the three positions of the apparatus and the sea lion's choice (Table 2). Analyses of the sea lion's responses to the three positions of the apparatus during each block of sessions yielded significant deviations from equal distributions for blocks A, B, C, D, $\mathrm{G}, \mathrm{H}$, and $\mathrm{J}$ and for the sum of all responses during Blocks A-J $\left[\chi^{2}(2)\right.$; for results, see Table 3$]$. There was a general tendency of the sea lion to choose the central position of the apparatus during the first experimental stage.

In the second experimental stage (one-odd/five-trial problems), the sea lion failed to reach criterion during 24 sessions in which the positive stimulus could appear in all three positions (three-position oddity, Block K; Figure 3). Performance increased from $23.3 \%$ correct choices in the 1 st session to a maximum of $76.6 \%$ in the 23 rd session; it decreased again to $60 \%$ correct choices in the last session, however. As the sea lion started to show poor motivation, we decided to terminate this experimental stage without reaching criterion and to continue with a two-position oddity task. After a clear breakdown of performance in the first session ( $20 \%$ correct choices), the sea lion finally reached criterion in the 10th session (Block L). In the three-position oddity condition of this experimental stage (Block K, 720 trials), chi-square tests yielded highly significant deviations from equal distributions of the sea lion's reactions to the three positions with respect to presentation of the correct stimulus on the three positions of the apparatus [left position, $\chi^{2}(2, N=213)=36.08, p<$ .001 ; central position, $\chi^{2}(2, N=166)=35.60, p<.001$; right position, $\left.\chi^{2}(2, N=341)=31.20, p<.001\right]$. Thus, there was a significant correlation between presentation of stimuli on the three positions of the apparatus and the sea lion's choice (Table 4). An analysis of the sea lion's reactions to the three positions of the apparatus during Block K yielded a highly significant deviation from an equal distribution $\left[\chi^{2}(2, N=720)=68.36, p<.001\right]$.

Table 2

Sea Lion's Choices in the First Experimental Stage (Blocks A-J) Correlated With Presentation of the Correct Stimulus (S+) on the Three Apparatus Positions

\begin{tabular}{lcccr}
\hline & \multicolumn{3}{c}{ Reactions } & \\
\cline { 2 - 4 } Position & To Left & To Center & To Right & Total \\
\hline S+ on left & $213^{*}$ & 94 & 93 & 400 \\
S+ central & 49 & $257^{*}$ & 94 & 400 \\
S+ on right & 60 & 117 & $223^{*}$ & 400 \\
Total & 322 & 468 & 410 & 1,200 \\
\hline
\end{tabular}

${ }^{*}$ Correct choices.

Table 3

Sea Lion's Reactions to the Three Positions of the Apparatus in the First Experimental Stage (Blocks A-J)

\begin{tabular}{|c|c|c|c|c|c|}
\hline \multirow[b]{2}{*}{ Problem } & \multicolumn{3}{|c|}{ Reactions } & \multirow[b]{2}{*}{ Total } & \multirow[b]{2}{*}{$\chi^{2}$} \\
\hline & To Left & To Center & To Right & & \\
\hline $\mathrm{A}^{*}$ & 31 & 87 & 32 & 150 & 41.08 \\
\hline $\mathrm{B}^{*}$ & 13 & 33 & 14 & 60 & 12.7 \\
\hline $\mathrm{C}^{*}$ & 54 & 64 & 92 & 210 & 11.09 \\
\hline $\mathrm{D}^{*}$ & 33 & 40 & 17 & 90 & 9.27 \\
\hline $\mathrm{E}$ & 36 & 31 & 23 & 90 & 2.87 \\
\hline $\mathrm{F}$ & 10 & 10 & 10 & 30 & 0 \\
\hline $\mathrm{G}^{*}$ & 43 & 84 & 53 & 180 & 15.23 \\
\hline $\mathrm{H}^{*}$ & 57 & 57 & 96 & 210 & 14.49 \\
\hline I & 21 & 16 & 23 & 60 & 1.3 \\
\hline $\mathrm{J}^{*}$ & 24 & 46 & 50 & 120 & 9.8 \\
\hline Total $^{*}$ & 322 & 468 & 410 & 1,200 & 27.02 \\
\hline
\end{tabular}

*Problems with significant deviations from an equal distribution over the three positions as determined by $\chi^{2}$ test. 


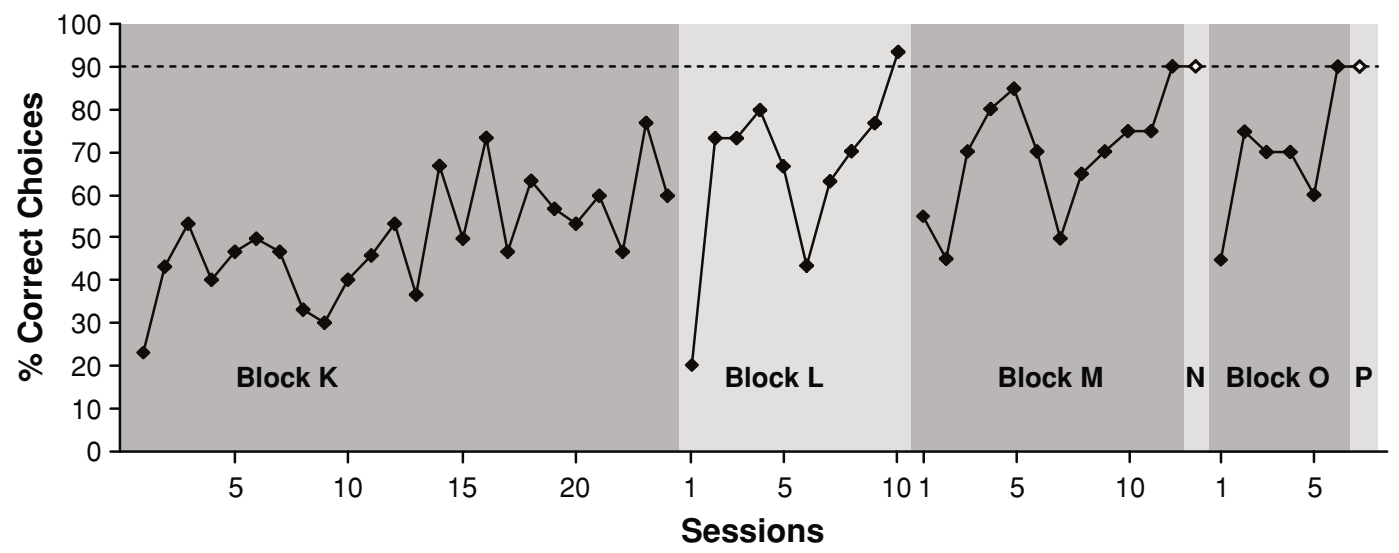

Figure 3. Learning curves of our sea lion. Filled symbols denote experiments with familiar stimuli; open symbols denote experiments with completely new stimuli (transfer tests, Blocks $\mathbf{N}$ and $\mathbf{P}$ ).

Thus, the sea lion chose the right position of the apparatus significantly more often than the other positions in this block. In Block L, an analysis of the responses to the two outer positions of the apparatus did not yield a significant deviation from an equal distribution $\left[\chi^{2}(1, N=266)=\right.$ $3.85, p>.05]$.

Blocks $\mathrm{K}$ and $\mathrm{L}$ were also analyzed for changing performance over the course of the 204 problems used in these blocks (interproblem learning) as well as for changing performance within the five trials of each problem (intraproblem learning). The sea lion's average performance was plotted separately for the first to fifth trials across Blocks K and L (204 problems, subdivided in five clusters of 36 problems and one cluster of 24 problems) (Figure 4A). Here, all five plots show the sea lion's increasing performance in the course of this experimental stage. Linear regression analyses yielded slopes of $m=2.62$ for the first-trial plot (correlation coefficient: $r=.67$ ); $m=$ 6.11 for the second-trial plot $(r=.763) ; m=6.27$ for the third-trial plot $(r=.92) ; m=5.72$ for the fourth-trial plot $(r=.90)$; and $m=9.68$ for the fifth-trial plot $(r=.9)$.

Furthermore, the sea lion's average performance in each of the five trials conducted with every problem was plotted separately for each of the six clusters of problems (Figure 4B). Although the average performance in the first four clusters of problems (Problems 1-144) does not show a clear tendency to increase over the five trials conducted

Table 4

Sea Lion's Choices in the Second Experimental Stage (Block K), Correlated With Presentation of the Correct Stimulus (S+) on the Three Apparatus Positions

\begin{tabular}{lcccc}
\hline & \multicolumn{3}{c}{ Reactions } & \\
\cline { 2 - 4 } & To Left & To Center & To Right & Total \\
\hline S+ on left & $112^{*}$ & 43 & 85 & 240 \\
S+ central & 55 & $91^{*}$ & 94 & 240 \\
S + on right & 46 & 32 & $162^{*}$ & 240 \\
Total & 213 & 166 & 341 & 720 \\
\hline
\end{tabular}

${ }^{*}$ Correct choices. with every problem, the average performance increases slightly over the five trials in the fifth cluster of problems (from an average of 53\% correct choices on the first trial to an average of $67 \%$ correct choices on the fifth trial, Problems 145-180). In the sixth cluster of problems (Problems 181-204), average performance clearly increases over the five trials (from an average of $58 \%$ on the first trial to an average of $92 \%$ on the fifth trial) and reaches $80.5 \%$ by the second trial.

In the first part of the third experimental stage, presented with one-trial problems made of familiar stimuli in the two-position oddity condition (Block M), the sea lion reached criterion ( $90 \%$ correct choices) after 12 sessions (20 trials per session). In a transfer test (Block N) conducted with 20 problems composed of completely new stimuli, the sea lion immediately reached the criterion. In the second part of the third experimental stage (Blocks $\mathrm{O}$ and $\mathrm{P}$ ) with one-trial problems using familiar stimuli in the three-position oddity condition (Block O), criterion was reached again after 6 sessions. In the final transfer test (Block P) with 20 three-position oddity problems composed of completely new stimuli, the sea lion reached the criterion immediately.

In the three-position oddity condition of this experimental stage (Blocks O and P, 140 trials), chi-square tests yielded significant deviations from equal distributions of the sea lion's reactions to one of the three positions with respect to presentation of the correct stimulus on the three positions of the apparatus [left position, $\chi^{2}(2, N=$ $46)=43.79, p<.001$; central position, $\chi^{2}(2, N=46)=$ $42.25, p<.001$; right position, $\chi^{2}(2, N=70)=28.23$, $p<.001]$. Thus, there was a clear correlation between presentation of stimuli on the three positions of the apparatus and the sea lion's choice (Table 5).

An analysis of the sea lion's reactions to the two outer positions of the apparatus during Blocks $\mathrm{M}$ and $\mathrm{N}$ yielded a significant deviation from an equal distribution $\left[\chi^{2}(1, N=\right.$ $241)=6.98, p<.01]$. An analysis of the sea lion's reactions to the three positions of the apparatus during Blocks $\mathrm{O}$ and $\mathrm{P}$ yielded a highly significant deviation from an equal 


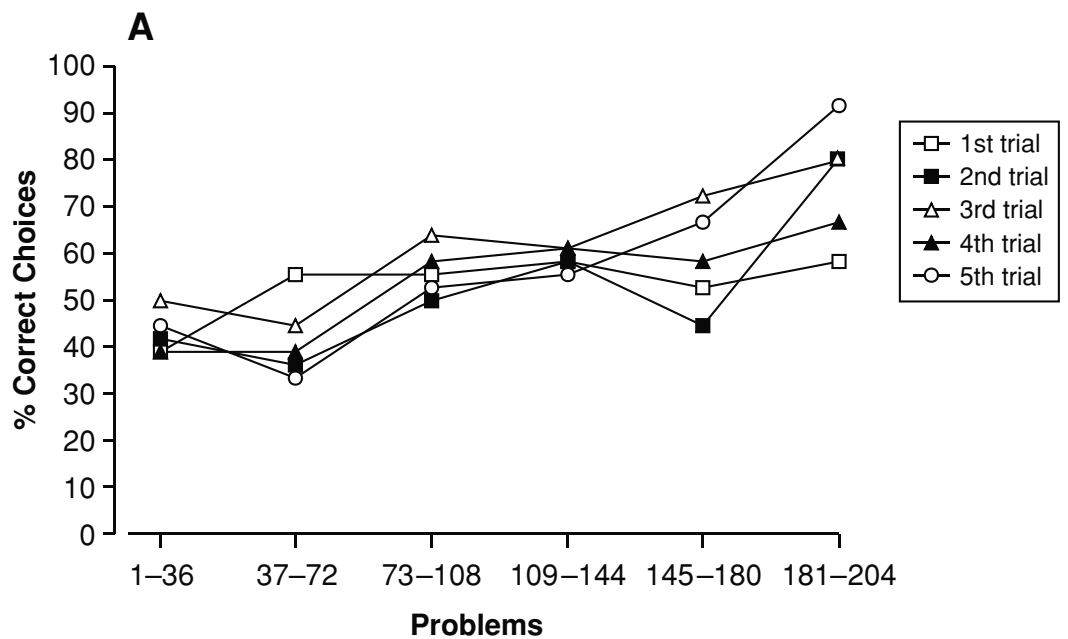

B

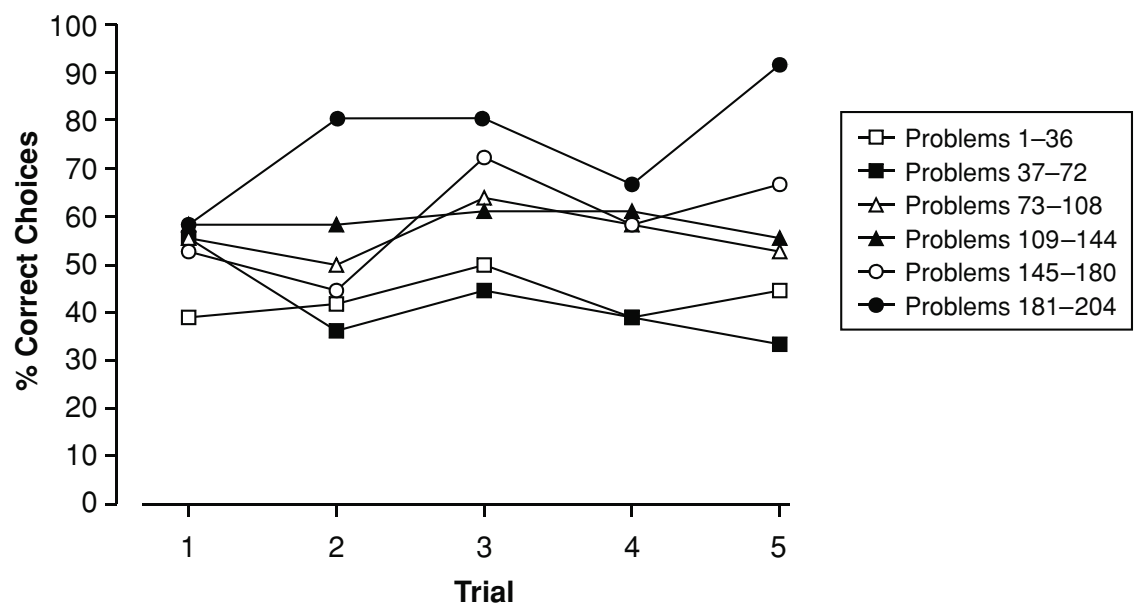

Figure 4. (A) Plot of the sea lion's learning curves for Trials 1-5 conducted with each problem during Blocks K and L. (B) Plot of the sea lion's performance (averaged over six clusters of problems) in each of the five successive trials conducted with every problem.

distribution $\left[\chi^{2}(2, N=140)=22.69, p<.001\right]$. Thus, the sea lion reacted to the right position of the apparatus significantly more often (on 70 trials) than to the left (on 46 trials) or to the central position (on 24 trials).

\section{DISCUSSION}

An interpretation of the sea lion's performance and choice behavior in the three stages of the study suggests that the sea lion mastered the oddity task in the first stage by learning specific stimulus properties and in the second stage by learning set formation, but that it presumably applied an oddity concept in the third experimental stage.

\section{The Sea Lion's Performance During the Study}

Although the sea lion was experimentally naive concerning visual tasks and cognitive test paradigms, it learned the basic oddity task with little difficulty. The 10 one-odd problems presented in the first experimental stage were solved within a total of 1,200 trials. Although the sea lion needed 150 trials to solve the first one-odd problem and even more trials to solve some of the other problems $(210,180$, and 210 trials, for Problems C, G, and $\mathrm{H}$, respectively), the average of 120 trials/problem is in the same range as that found in oddity-learning rats

Table 5

Sea Lion's Choices in the Third Experimental Stage (Blocks $\mathrm{O}$ and $\mathrm{P}$ ), Correlated With Presentation of the Correct Stimulus $(\mathrm{S}+)$ on the Three Apparatus Positions

\begin{tabular}{lcccr}
\hline & \multicolumn{3}{c}{ Reactions } & \\
\cline { 2 - 4 } \multicolumn{1}{c}{ Position } & To Left & To Center & To Right & Total \\
\hline S+ on left & $33^{*}$ & 0 & 16 & 49 \\
S+ central & 9 & $23^{*}$ & 10 & 42 \\
S+ on right & 4 & 1 & $44^{*}$ & 49 \\
Total & 46 & 24 & 70 & 140 \\
\hline
\end{tabular}

${ }^{*}$ Correct choices. 
(Thomas \& Noble, 1988; 4 rats; median trials to criterion on 10 visual one-odd problems were 50-180 trials) and even better than the learning by pinnipeds tested in some other studies. For example, we recently presented evidence for identity concept formation in a harbor seal, which mastered a matching procedure with the first two objects in 10 sessions (450 trials) (Mauck \& Dehnhardt, 2005). Similarly, a California sea lion in a study on mental rotation (Mauck \& Dehnhardt, 1997) needed 10 sessions of matching training to learn the initial discriminations between the first two stimuli (240 trials to criterion). And in a study by Pack et al. (1991), although the performance of a California sea lion increased within the first 24 sessions ( 503 trials) with the first three stimuli used during the acquisition phase of a matching experiment, the sea lion only reached the defined criterion in an additional 269 trials and after the third stimulus was eliminated from the object pool.

In the second experimental stage, the sea lion was presented with six new problems in every session (a one-odd/ five-trial task). In the three-position oddity condition of this task, although performance slowly increased following a typical learning curve, our sea lion failed to reach criterion within 24 sessions ( 720 trials). Though not presented in a learning curve allowing a direct comparison, the overall performance of the 3 rats tested by Thomas and Noble (1988) in the olfactory oddity task obviously did not show a clear increase over the 15 blocks of 20 fivetrial problems. Owing to the use of five-trial problems in the present study, it also seems difficult to compare the sea lion's performance to that of other marine mammals in similar tasks. However, in Blocks $\mathrm{C}-\mathrm{G}$ of the recent study by Mauck and Dehnhardt (2005), our harbor seal was presented with each problem 10 times/session (although in the respective matching procedure, comparison stimuli were presented only on the two outer positions of the apparatus as opposed to the three-position oddity described here). After having learned the matching task within 840 trials (Blocks $\mathrm{C}$ and D) with two stimulus sets of six mostly new objects, the harbor seal reached criterion almost immediately in the following blocks (E, F, G; six completely new objects were used to present each problem 10 times/session). It can be presumed that the sea lion in the present study might have reached criterion in the three-position oddity condition with more five-trial problems. However, two-position oddity improves the chances of correct responding, owing to the elimination of the central position as a rewarded choice, and it may be speculated that the Gestalt resulting from the two non-odd and perceptually identical objects' being adjacent offers advantages in discrimination (Thomas \& Crosby, 1977). As our sea lion started to show poor motivation, we decided to change the experimental procedure accordingly. Following this change, the sea lion's performance in the two-position oddity condition dropped down to $20 \%$ correct choices in the first session, but clearly increased by the second session and reached criterion within 10 sessions. This was considered an appropriate level for the change to one-trial problems; how- ever, the two-position oddity condition was maintained in order not to demand too much of the sea lion. As could be expected, this change in experimental design again had a negative effect on the sea lion's performance (55\% correct choices on the first session), but performance in the two-position condition increased to criterion within 12 sessions (240 trials, Block M) and was maintained at that high level on the transfer session with 20 new problems (Block N), thus possibly providing evidence for a conceptualization of oddity. The following change in experimental procedure to a three-position oddity with one-trial problems consisting of familiar stimuli (Block O) was intended as the last preparatory step for one-trial tests with completely new stimuli (Block P). This preparation was completed when the sea lion reached criterion within six sessions. Only one transfer session was necessary to provide evidence for oddity conceptualization in the threeposition condition as well.

\section{The Sea Lion's Learning Strategies in the Course of the Study}

In the first experimental stage, there was no decrease in the number of trials to criterion over the 10 problems. Trials to criterion varied between 30 and 210 trials. Therefore, it can be assumed that the sea lion found the 10 problems to be of differing difficulty and used specific stimulus parameters to learn each of the 10 problems. Concerning the sea lion's side preferences, it is interesting that there were no significant deviations from equal distributions of the sea lion's responses to the three positions of the apparatus in the problems that the sea lion solved rather quickly (Problem E, 90 trials; Problem F, 30 trials; Problem I, 60 trials). Position preferences can be used by a test animal to initially structure the information presented in the task (cf. King \& Fobes, 1975; Poucet, Buhot-Averseng, $\&$ Thinus-Blanc, 1983). It can be assumed that specific stimulus properties in the respective problems were sufficiently discriminable to the sea lion that there was no need to develop a side preference as an assisting strategy. The clearest side preference was found in the very first problem $\left[\chi^{2}(2, N=150)=41.08\right]$, probably indicating that the sea lion had some initial problems while searching for the relevant information to solve the task.

In the second experimental stage, the sea lion's opportunities to learn specific stimulus properties were limited to five successive trials on each problem. As indicated by a strong preference for the right position of the apparatus in the three-position oddity condition (Block K), this change in experimental design resulted in a search for other strategies that might provide a solution to the task. However, the sea lion obviously had fewer problems with the two-position oddity condition, because-besides its reaching criterion within only 10 sessions - there was no significant side preference. This may indicate that the sea lion had learned how to approach the task over the course of Blocks K and L. This view is supported by the analysis of both changing performance in the course of presentation of the 204 problems (interproblem learning) and 
changing performance within the five-trial presentation of the problems (intraproblem learning) (Figures 4A and 4B). Both analyses suggest that our sea lion learned how to solve the task efficiently: First, performance increased over the course of the respective blocks, most clearly on the fifth trial of every problem, but performance increased less clearly on the first trial than on the following trial of every problem. Second, performance over the five trials increased most clearly for the last cluster of problems (Problems 181-204), reaching an average of $92 \%$ correct choices on the fifth trial and high values on the second trial. This leads us to conclude that our sea lion was able to increase its overall performance by learning set formation during Blocks $\mathrm{K}$ and $\mathrm{L}$.

Learning set formation was assumed to be the reason for failure of concept formation in several previous studies. Bailey and Thomas (1998) reasoned that their rats did not perform conceptually in their oddity task because there might have been insufficient incentive to do so. As a result of being presented with every problem more than once and of the corresponding development of a learning set, the rats were able to respond correctly on the second trial and thereafter, and thus they were subsequently rewarded most of the time. This could be avoided only by using onetrial problems. In this respect, a visual oddity task has the obvious advantage of enabling the presentation of a large pool of trial-unique problems that would be more difficult with olfactory stimuli because of the limited number of available odoriferous substances.

When our sea lion was presented with trial-unique problems in Blocks M-P, there was also a strong overall side preference for the right position of the apparatus. Nevertheless, this side preference was eventually abandoned in favor of an oddity concept, since the sea lion reached the criterion within 11 and 6 sessions in Blocks $\mathrm{M}$ and $\mathrm{O}$, respectively, and successfully transferred this high performance to sessions with completely new stimuli (Blocks $\mathrm{N}$ and P). However, oddity concept formation might have occurred only in the three-position oddity condition, because the two-position oddity task could have been solved by a perceptual mechanism similar to that already suggested by Nissen, Blum, and Blum (1948) for matching in chimpanzees. Similarly, our sea lion could have learned to avoid the perceived "larger" entity of neighboring same stimuli and to choose the "smaller" odd stimulus. In principal, the sea lion could have applied the same strategy on the threeposition oddity task on the trials when the $\mathrm{S}+$ was in the left or right position, and on the trials when there was no larger area (central S+ trials), it could have selected the middle stimulus. However, given that the sea lion reached $75 \%$ correct choices by the second session of Block O, it must have learned to apply the additional rule on $\mathrm{S}+$ central trials in only one session of 20 trials. Furthermore, it seems questionable whether the combined usage of two separate rules would be less complex than usage of the oddity concept. Thus, oddity concept formation can be concluded with fair certainty in the three-position oddity condition from the successful transfer session in Block P, where the criterion was met with trial-unique problems using novel stimuli.

\section{Some Ecological Implications of Oddity Conceptualization}

In our recent presentation of sameness conceptualization in a harbor seal (Mauck \& Dehnhardt, 2005), we have argued that the conditions required for experimental evidence of identity concept formation (i.e., conditionality and similar history of stimuli, sufficiently large sample size of first-trial data; see, e.g., Kastak \& Schusterman, 1992; Schusterman \& Kastak, 1995) are in fact not very likely to be met in the wild. Thus, the lack of natural application of concepts in an animal's environment may have led to the difficulties met during respective experiments. This argument also holds for the oddity concept, although a conceptualized application of oddity (which can be assumed to be the reversal of the sameness concept at least in this specific context) could - for example - enhance a predator's foraging success in hunting gregarious prey. In fact, predator confusion is enhanced by the similarity of the appearance of group members (Godin, 1997). Group members that are odd in size (Theodorakis, 1989), color (Landeau \& Terborgh, 1986; McRobert \& Bradner, 1998; Mueller, 1975), or behavior (Parish, Strand, \& Lott, 1989) suffer disproportionately higher rates of attack. However, being prey opportunists, sea lions feed on a variety of both pelagic and benthic prey of rather small size, resulting in the need to capture many prey fish, not only single weak individuals. To our knowledge, the foraging strategies of sea lions hunting swarm fish such as herring have not been described in detail (for reviews on marine mammal feeding ecology, see Bowen, Read, \& Estes, 2002; Boyd, 1993). Thus, there seems to be no obvious adaptive value of an oddity concept applied by foraging sea lions for the detection of aberrant fish.

Instead, similar to the capability for identity conceptualization, the capability to conceptualize oddity may be a close psychological descendent of the phylogenetically ancient capability to conceptualize "familiarity and novelty" (Delius, 1994). The evidence for oddity conceptualization in our sea lion could be explained as we have suggested for the identity concept formation capability recently shown for a harbor seal (Mauck \& Dehnhardt, 2005). Accordingly, this kind of concept formation might be indicative of a highly developed information processing system, and the general resulting cognitive economy in decision processes could be adaptive per se. The capability to conceptualize "oddity" might be experimentally demonstrable, given appropriate methods both in other marine mammal species-simply because there was no need to select against this trait in the marine environment - and in other animals assumed to be incapable of this conceptualization.

\section{REFERENCES}

Bailey, A. M., \& Thomas, R. K. (1998). An investigation of oddity concept learning in rats. Psychological Record, 48, 333-344.

Barsalou, L. W. (1992). Cognitive psychology: An overview for cognitive scientists. Hillsdale, NJ: Erlbaum.

Bourne, L. E. (1970). Knowing and using concepts. Psychological Review, 77, 546-556. 
Bowen, W. D., Read, A. J., \& Estes, J. A. (2002). Feeding ecology. In A. R. Hoelzel (Ed.), Marine mammal biology: An evolutionary approach (pp. 217-246). Oxford: Blackwell.

BoYD, I. L. (1993). Marine mammals: Advances in behavioural and population biology. Oxford: Oxford University Press, Clarendon Press.

Delius, J. D. (1994). Comparative cognition of identity. In P. Bertelson, P. Eelen, \& G. d'Ydewalle (Eds.), International perspectives on psychological science: Vol. 1. Leading themes (pp. 25-40). Hillsdale, NJ: Erlbaum.

Domuan, M. (1998). The principles of learning and behavior. Pacific Grove, CA: Brooks/Cole.

FoDOR, J. A. (1998). Concepts: Where cognitive science went wrong. Oxford: Oxford University Press.

GAGNÉ, R. M. (1970). The conditions of learning. New York: Holt, Rinehart \& Winston.

Gellerman, L. W. (1933). Chance orders of alternating stimuli in visual discrimination experiments. Journal of Genetic Psychology, 42, 206-208.

Godin, J.-G. J. (1997). Evading predators. In J.-G. J. Godin (Ed.), Behavioural ecology of teleost fishes (pp. 191-236). Oxford: Oxford University Press.

KastaK, D. A., \& Schusterman, R. J. (1992). Comparative cognition in marine mammals: A clarification on match-to-sample tests. Marine Mammal Science, 8, 414-417.

Kastak, D. [A.], \& Schusterman, R. J. (1994). Transfer of visual identity matching-to-sample in two California sea lions (Zalophus californianus). Animal Learning \& Behavior, 22, 427-435.

KING, J. E., \& FoBES, J. L. (1975). Hypothesis analysis of samenessdifference learning-set by capuchin monkeys. Learning \& Motivation, 6, 101-113.

KoffKa, K. (1935). Principles of Gestalt psychology. New York: Harcourt, Brace.

Landeau, L., \& Terborgh, J. (1986). Oddity and the "confusion effect" in predation. Animal Behaviour, 34, 1372-1380.

Lombardi, C. M., Fachinelli, C. C., \& Delius, J. D. (1984). Oddity of visual patterns conceptualized by pigeons. Animal Learning \& Behavior, 12, 2-6.

Mauck, B., \& Dehnhardt, G. (1997). Mental rotation in a California sea lion (Zalophus californianus). Journal of Experimental Biology, 200, 1309-1326.

Mauck, B., \& DehnhardT, G. (2005). Identity concept formation during visual multiple-choice matching in a harbor seal (Phoca vitulina). Learning \& Behavior, 33, 428-436.

MCROBERT, S. P., \& BRADNER, J. (1998). The influence of body coloration on shoaling preferences in fish. Animal Behaviour, 56, 611-615.

Medin, D. L. (1989). Concepts and conceptual structure. American Psychologist, 44, 1469-1481.

Medin, D. L., \& Coley, J. D. (1998). Concepts and categorization. In J. Hochberg (Ed.), Perception and cognition at century's end: History, philosophy, theory (pp. 402-432). San Diego: Academic Press.

Mueller, H. C. (1975). Hawks select odd prey. Science, 188, 953-954.

Nissen, H. W., Blum, J. S., \& Blum, R. A. (1948). Analysis of matching behavior in chimpanzee. Journal of Comparative \& Physiological Psychology, 41, 62-74.

Oden, D. L., Thompson, R. K., \& Premack, D. (1990). Infant chimpanzees spontaneously perceive both concrete and abstract same/different relations. Child Development, 61, 621-631.

Pack, A. A., Herman, L. M., \& Roitblat, H. L. (1991). Generalization of visual matching and delayed matching by a California sea lion (Zalophus californianus). Animal Learning \& Behavior, 19, 37-48.
Parish, J. K., Strand, S. W., \& LotT, J. L. (1989). Predation on a school of flat-iron herring, Harengula thrissina. Copeia, 1989, 1089-1091.

Pisacreta, R., LefaVe, P., Lesneski, T., \& Potter, C. (1985). Transfer of oddity learning in the pigeon. Animal Learning \& Behavior, 13, 403-414.

Poucet, B., Buhot-Averseng, M. C., \& Thinus-Blanc, C. (1983). Food-searching behavior of cats in a multiple-choice elimination problem. Learning \& Motivation, 14, 140-153.

Rensch, B. (1973). Gedächtnis, Begriffsbildung und Planhandlungen bei Tieren. Berlin: Paul Parey.

Roitblat, H. L., \& Fersen, L. von (1992). Comparative cognition: Representations and processes in learning and memory. Annual Review of Psychology, 43, 671-710.

Rosch, E. (1978). Principles of categorization. In E. Rosch \& B. B. Lloyd (Eds.), Cognition and categorization (pp. 27-48). Hillsdale, NJ: Erlbaum.

Schusterman, R. J., \& Kastak, D. A. (1995). There is no substitute for an experimental analysis of marine mammal cognition. Marine Mammal Science, 11, 263-267.

Siegler, R. S., \& Crowley, K. (1991). The microgenetic method: A direct means for studying cognitive development. American Psychologist, 46, 606-620.

Smirnova, A. A., Lazareva, O. F., \& Zorina, Z. A. (2000). Use of number by crows: Investigation by matching and oddity learning. Journal of the Experimental Analysis of Behavior, 73, 163-176.

Steirn, J. N., \& Thomas, R. K. (1990). Comparative assessments of intelligence: Performances of Homo sapiens sapiens on hierarchies of oddity and sameness-difference tasks. Journal of Comparative Psychology, 104, 326-333.

THEODORAKIS, C. W. (1989). Size segregation and the effects of oddity on predation risk in minnow schools. Animal Behaviour, 38, 496-502.

THomas, R. K. (1980). Evolution of intelligence: An approach to its assessment. Brain, Behavior, \& Evolution, 17, 454-472.

Thomas, R. K. (1996). Investigating cognitive abilities in animals: Unrealized potential. Cognitive Brain Research, 3, 157-166.

Thomas, R. K., \& BoyD, M. G. (1973). A comparison of Cebus albifrons and Saimiri sciureus on oddity performance. Animal Learning \& Behavior, 1, 151-153.

Thomas, R. K., \& Crosby, T. N. (1977). Absolute versus relative class conceptual behavior in squirrel monkeys (Saimiri sciureus). Animal Learning \& Behavior, 5, 265-271.

Thomas, R. K., \& Frost, T. (1983). Oddity and dimension abstracted oddity (DAO) in squirrel monkeys. American Journal of Psychology, 96, 51-64.

Thomas, R. K., \& Noble, L. M. (1988). Visual and olfactory oddity learning in rats: What evidence is necessary to show conceptual behavior? Animal Learning \& Behavior, 16, 157-163.

Thompson, R. K. R. (1995). Natural and relational concepts in animals. In H. L. Roitblat \& J.-A. Meyer (Eds.), Comparative approaches to cognitive science (pp. 175-224). Cambridge, MA: MIT Press.

Turner, M. B. (1967). Philosophy and the science of behavior. New York: Appleton-Century-Crofts.

Zentall, T. R., Galizio, M., \& Critchfield, T. S. (2002). Categorization, concept learning, and analysis: An introduction. Journal of the Experimental Analysis of Behavior, 78, 237-248.

(Manuscript received March 31, 2005; revision accepted for publication September 27, 2005.) 